\title{
Passiflora fissurosa, uma nova espécie de Passifloraceae para o Amazonas, Brasil
}

\author{
Maria Anália Duarte de SOUZA ${ }^{1}$, Michael John Gilbert HOPKINS² \\ RESUMO \\ Passiflora fissurosa M.A.D.Souza sp. nov., até o momento conhecida apenas da Reserva Florestal Adolpho Ducke, no Amazonas, \\ Brasil, é descrita e ilustrada. Foi inserida no Subgênero Passiflora, Superseção Passiflora, Seção Laurifoliae e Série Laurifoliae, por \\ apresentar folhas simples e inteiras, pecíolo biglandular, brácteas foliáceas, livres, maiores que $1 \mathrm{~cm}$, pertencendo ao grupo de \\ espécies com as duas séries externas da corona subiguais. Morfologicamente é semelhante a $P$. nitida, que difere pelo opérculo \\ horizontal-encurvado com margem ereto-divergente, anel nectarífero presente, límen vertical e ovário glabro. A designação \\ do epíteto deve-se à característica do ritidoma, suberoso e profundamente fissurado, característica somente encontrada em $P$. \\ phellos, também pertencente à Série Laurifoliae, mas do grupo de espécies com a primeira série da corona menor que a segunda.
}

PaLAVRAS-CHAVE: Passiflora fissurosa, Série Laurifoliae, Reserva Florestal Adopho Ducke

\section{Passiflora fissurosa, a new species of Passifloraceae from Amazon, Brazil}

\section{ABSTRACT}

Passiflora fissurosa M.A.D. Souza sp. nov., presently known only from the Adolpho Ducke Forest Reserve in Amazonian Brazil, is described and illustrated. P. fissurosa belongs in the subgenus Passiflora, Supersection Passiflora, Section Laurifoliae and Series Laurifoliae, with simple, entire leaves, a biglandular petiole, free foliaceous stipules larger than $1 \mathrm{~cm}$, in the group of species with the outer two series of the corona sub-equal. Morphologically it resembles P. nitida, which differs by the horizontal curved with erect-divergent margin operculum, the presence of a nectariferous ring, vertical limen and glabrous ovary. The epithet is derived from the characteristic of the bark, which is corky and profoundly fissured, which is showed only by $P$. phellos of the Laurifoliae group which has the first series of the corona smaller than the second.

KEYWORDS: Passiflora fissurosa, Série Laurifoliae, Reserva Florestal Adopho Ducke

1 Universidade Federal do Amazonas. analia.duarte@yahoo.com.br

2 Instituto Nacional de Pesquisas da Amazônia. mikehopkins44@hotmail.com 


\section{INTRODUÇÃO}

A família Passifloraceae contém cerca de 18 gêneros e 630 espécies, de ocorrência pantropical, com distribuição descontínua nos trópicos e subtrópicos (Ocampo et al. 2007). No novo mundo, a maioria das espécies ocorre nas Américas Central e Sul, crescendo até a $3800 \mathrm{~m}$ acima do nível do mar (Holm-Nielsen 1988; Deginani 2001). Na Regiáo Neotropical ocorrem quatro gêneros: Mitostemma Mast. (3 espécies); Dilkea Mast. (6); Ancistrothyrsus Harms (3), endêmico na Região Amazônica; e Passiflora L. (ca. 520), presente também na África, Ásia e Austrália (Cervi 1997; Ulmer e MacDougal 2004). Para o Brasil foram registradas cerca de 140 espécies por Cervi (2006), 127 (Ocampo et al. 2007) e, finalmente, 135 espécies registradas na Flora do Brasil (Cervi et al. 2010). Para o Amazonas foram registradas 51, sendo o estado com maior diversidade e onde apenas Mitostemma não está representado. Este nível de diversidade está bem representado na Reserva Florestal Adolpho Ducke, que abriga três gêneros e 20 espécies (Ribeiro et al. 1999). Visto o grau de devastação que os ecossistemas amazônicos vêm sofrendo, torna-se urgente um inventário mais abrangente desta família na região.

As espécies são caracterizadas pela presença de gavinhas axilares, folhas polimórficas, estípulas e brácteas pequenas ou foliáceas, flores com corona filamentosa em uma a várias séries, estames cinco a oito, livres ou conados, e ovário tricarpelar com placentaçáo parietal. A série Laurifoliae apresenta folhas simples com margem inteira ou serrulada, pecíolo biglandular, brácteas foliáceas maiores que $1 \mathrm{~cm}$, livres, margem inteira ou dentada, cálice campanulado, curto, corona de filamentos variegados e bem desenvolvidos, opérculo incurvado com margem ereta, estiletes livres e frutos grandes (Cervi 1997).

O objetivo deste trabalho foi descrever uma nova espécie de Passifloraceae, Passiflora fissurosa Souza, bem como posicionála, com base em atributos morfológicos, dentro do subgênero Passiflora.

\section{MATERIAL E MÉTODOS}

Amostras deste novo táxon foram coletadas na Reserva Florestal Adolpho Ducke (RFAD, 02 ${ }^{\circ} 53^{\prime}$ S e 59 $58^{\circ}$ W), situada ao norte do Município de Manaus, Amazonas, durante o Projeto Flora da Reserva Ducke (www.inpa.gov.br/projetos, 1993-1998).

A comparação entre $P$. fissurosa com outras espécies foi realizada com base na coleção do herbário INPA (Instituto Nacional de Pesquisas da Amazônia, Manaus-AM, Brasil) e nos tipos depositados nos herbários MO (Missouri Botanical Gardens, EUA), NY (New York Botanical Gardens, EUA), HUH (Havard University Herbarium, EUA), K (Kew Botanical Gardens, London, UK), IAN (Instituto Agronômico do Norte, Belém-PA, Brasil) e MG (Museu Goeldi, Belém-
PA, Brasil). Todo o material citado no cabeçalho taxonômico foi examinado.

A terminologia adotada para descrever as características foi baseada em Killip (1938) e Cervi (1997 e 2006). Nas descriçôes morfológicas foram usadas as medidas $\mathrm{mm}$ e $\mathrm{cm}$ (milímetro e centímetro, respectivamente) e as abreviaçóes diâm. (diâmetro), compr. (comprimento), larg. (largura), alt. (altura) e ca. (cerca de). A mensuração foi realizada em material fixado em álcool a 70 \% (flores) e herborizado (folhas).

\section{RESULTADOS E DISCUSSÃO}

Passiflora fissurosa M.A.D. Souza, sp. nov. Tipo: BRASIL. Amazonas: Manaus, Reserva Florestal Adolpho Ducke, S 0253' e W 5958', 10/III/1995, Al/fr., J.E.L. Ribeiro et al. 1561 (Holótipo INPA, Isótipos INPA, K). Figura 1A-C.

Passiflora fissurosa in subg. Passiflora ser. Laurifoliae pertinens. Haec species Passiflora nitida Kunth. similis; differt caulis erecto, suberoso, profunde fissurato; bracteis ovalibus sive ellipticis; paginis abaxialibus papillato-strigulosis, eis adaxialibus glabris; operculo tubuloso apicem fimbriato convergenti; ovario denso-canescenti (vs. glabrato in P. nitida).

Liana escandente, lenhosa. Caule ereto, $2 \mathrm{~cm}$ ou mais de DAP. Ritidoma profundamente fissurado, suberoso, com arestas de 2,5 cm alt., desprendendo fragmentos friáveis; casca viva fibrosa, espessada, castanho-avermelhada ou clara. Planta glabra (exceto o ovário). Ramos jovens verdes, fortemente estriados. Gavinhas verdes, lenhosas, cilíndricas. Estípulas cedo-decíduas, setáceo-subuladas, $5 \mathrm{~mm}$ compr. Folhas dísticas, pecíolo verde 1,2-1,5 cm compr., $1,5 \mathrm{~mm}$ diâm., biglandular próximo à base da lâmina, globosas e sésseis; lâmina discolor, face adaxial lustrosa, abaxial rugosa, brilhante ou opaca, coriáceo-rígidas, 9,4-11,5 cm compr., 5-6 cm larg., ovadas ou elípticas, base arredondado-truncada ou subcordada, margem inteira e levemente revoluta, com glândulas oceolares, ápice acuminado ou agudo, conduplicado, venação eucamptódroma, nervuras secundárias 7-8 pares, arqueadas, terciárias reticuladas ou falso-oblíquas, obscuras. Inflorescência uniflora com eixo principal reduzido; brácteas foliáceas, externamente verdes e papilo-estrigulosas, internamente rosadas e glabras, coriáceas, 2,3-2,6 cm compr., 0,9-1,5 cm larg., ovadas ou elípticas, base obtusa a arredondada, margem levemente serrilhada nos $2 / 3$ proximais, com glândulas maculares, 1,5-2 mm compr., 0,5-1 mm diâm., ápice agudo ou obtuso, cuculado, venação eucamptódroma; pedicelo 4,8 cm compr., $2 \mathrm{~mm}$ diâm., estriado. Flores ca. 12 $\mathrm{cm}$ diâm. Tubo verde-arroxeado, 0,5-1 cm compr., $1-1,2 \mathrm{~cm}$ diâm, campanulado. Sépalas verde-arroxeadas externamente, roxo-escuras internamente, região mediana carnosa, 4,4-4,7 cm compr., 1-1,4 cm larg., oblongas, liguliformes, margem inteira, ápice agudo e cuculado com apêndice subapical, $2 \mathrm{~mm}$ compr. Pétalas roxo-escuras com ápice branco externamente, 


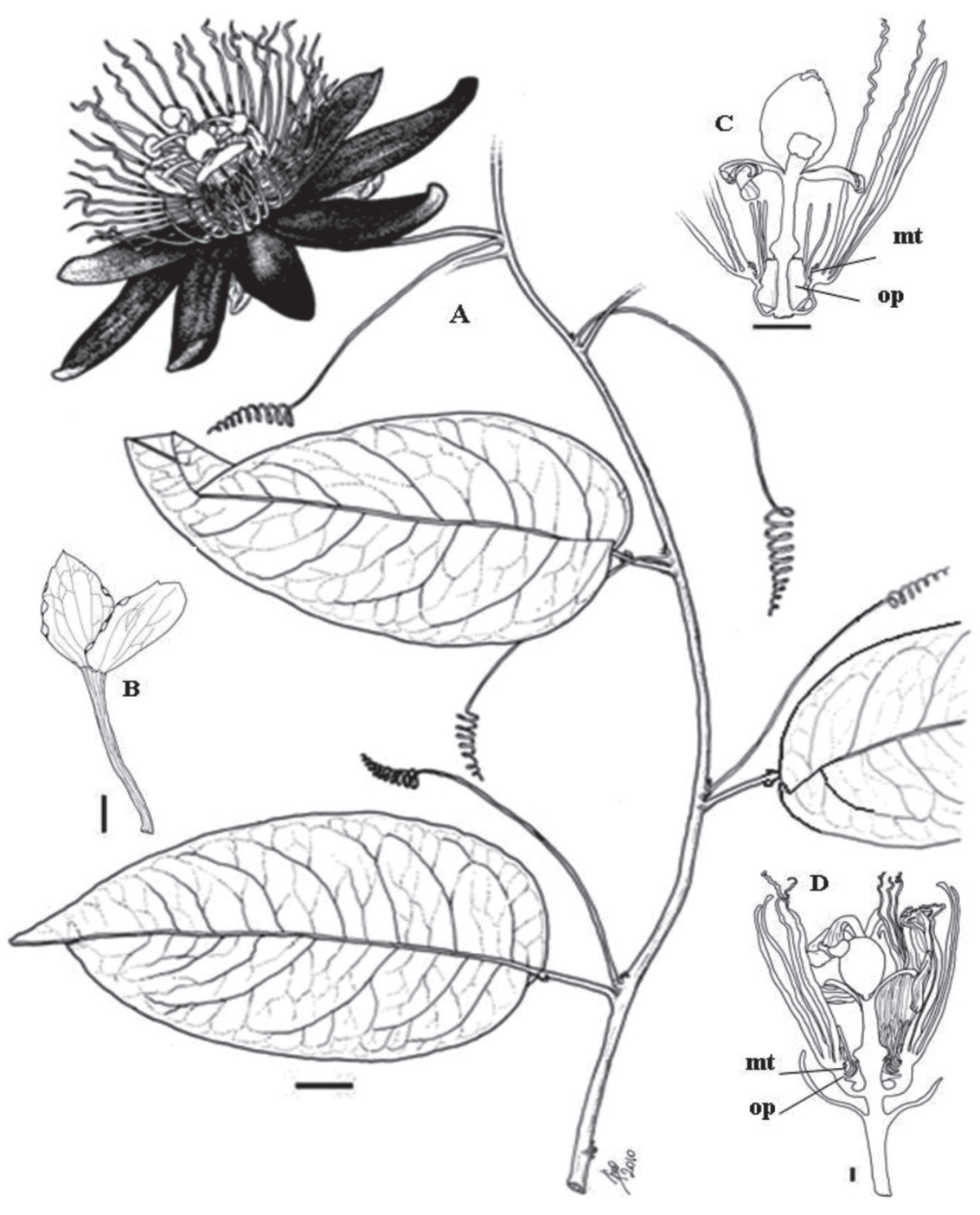

Figura 1 - Passiflora fissurosa M.A.D. Souza. A. hábito; B. brácteas; C. perfil floral com estiletes e duas anteras removidas. Notar 0 opérculo (op) de forma cupular e massa de tubérculos (mt); D. Passiflora nitida. Perfil floral. Barras = $1 \mathrm{~cm}$. (A,B,C: Ribeiro, J.E.L et al. 1561, INPA, K; D: Souza, M.A.D. et al. 315, INPA).

regiāo mediana longitudinal subcarnosa, 4-4,4 cm compr., 1 cm larg., oblongo-liguliformes, margem membranácea, ápice obtuso ou agudo, cuculado. Corona composta de ca. 8 séries: 2 séries externas filamentosas, filamentos com base vinácea, porção intermediária listrada de vináceo-purpúreo e branco, ápice subulado e roxo-claro, subcarnosos e papilosos, ca. 5 cm compr.; ca. 2 séries medianas filamentosas, filamentos 1-2 mm compr.; penúltimas séries constituídas de uma massa de tubérculos curtos; última série filamentosa, filamentos com base oblíqua, vináceo-purpúrea, porção intermediária branca, ápice vináceo-claro, ereto-divergentes, lobados e papilosos, 1,4 $\mathrm{cm}$ compr., $0,3 \mathrm{~mm}$ diâm. Opérculo tubular-cupuliforme, membranáceo, $1 \mathrm{~cm}$ alt., convergente, margem fimbriada. Límen abaixo da tróclea, anelar, horizontal. Anel nectarífero indistinto, porém ocorre a presença de uma câmara fechada na base do tubo, abaixo da base do opérculo. Andróforo verde-claro, anguloso, articulado próximo à base, 1,7-2,7 cm compr., 2-5 mm diâm., tróclea $3 \mathrm{~mm}$ alt., $4 \mathrm{~mm}$ diâm., filetes verde-claros, achatados, $1 \mathrm{~cm}$ compr., 2-3 mm larg., anteras brancas, 0,9-1,2 cm compr., $3 \mathrm{~mm}$ larg. Ovário creme, ovóide, 0,7-1,2 cm compr., 4-7 mm diâm., denso-canescente; estiletes brancos, purpúreo-arroxeados na base, $1 \mathrm{~cm}$ compr., $1 \mathrm{~mm}$ larg. na base, ápice dilatado; estigmas brancos, biglobosos, 2 $\mathrm{mm}$ diâm., papilosos. Frutos de aspecto globoso, ca. $5 \mathrm{~cm}$ compr. Sementes não vistas.

Conhecida somente da Reserva Ducke, na Amazônia Central, em floresta de terra firme, crescendo em ambiente de baixio em solo areno-argiloso. Atinge o dossel, alcançando 
aproximadamente 15 metros de altura. Flores, frutos jovens e restos de frutos maduros foram coletados no mês de março.

O epíteto refere-se à característica peculiar do ritidoma, profundamente fissurado com arestas de até $2,5 \mathrm{~cm}$ de largura e desprendimento de plaquetas friáveis, característica compartilhada apenas com $P$. phellos Feuillet, do grupo de Laurifoliae com a primeira série de corona menor que a segunda.

Passiflora fissurosa possui características morfológicas que a encaixam na Série Laurifoliae Killip ex Cervi, cujas espécies apresentam órgãos glabros, caule cilíndrico ou angular não alado, folhas simples com margem inteira a serreada, brácteas livres, foliáceas e maiores que $1 \mathrm{~cm}$, estípulas lineares ou setáceas cedo-decíduas e pecíolo biglandular. A nova espécie compartilha caracteres com $P$. nitida, como a presença de uma série da corona filamentosa maior que $5 \mathrm{~mm}$ entre as séries de massa de tubérculos e o opérculo, as duas séries externas filamentosas ultrapassando a corola, a presença de tróclea e o límen situado logo abaixo desta (Figura 1C). Entretanto, P. fissurosa diferencia-se de $P$. nitida por esta apresentar folhas espiraladas, ramos jovens angulosos e nervuras terciárias nitidamente oblíquas, ritidoma com desprendimento imperceptível, corona com duas séries curtofilamentosas após as duas externas, ca. $5 \mathrm{~mm}$ e 2-3 mm compr., respectivamente, seguidas de três séries tuberculiformes; a última série filamentosa com $1 \mathrm{~cm}$ compr., opérculo $4 \mathrm{~mm}$ alt., horizontal-encurvado com margem ereto-divergente e fimbrilada, límen anelar e vertical, anel nectarífero presente e ovário glabro (Figura 1D).

\section{Chave de identificação para a nova espécie}

1a. Ramos jovens e face abaxial da lâmina foliar com pêlos hispidulosos; lâmina com base cuneada; primeiro verticilo de corona 3/5 mais curto que o segundo (Amazônia Oriental; Feuillet 2004). P. phellos

1b. Planta com partes vegetativas glabras; lâmina com base arredondada ou cordada; verticilos externos subiguais.

2a. Ritidoma profundamente fissurado; opérculo tubular-cupuliforme com margem convergente e fimbrilada; nectarífero indistinto; ovário estriguloso (Amazônia Central, Brasil). P. fissurosa.

2b. Ritidoma com desprendimento imperceptível; opérculo horizontal-encurvado com margem divergente e fimbrilada; anel nectarífero presente; ovário glabro (Costa Rica até Goiás, Brasil; Killip 1938). P. nitida.

\section{AGRADECIMENTOS}

Aos governos brasileiro e britânico que, no âmbito do Projeto Flora da Reserva Ducke, financiaram as pesquisas nos herbários do Missouri Botanical Gardens (MO), New York Botanical Gardens (NY), Havard University Herbaria (HUH), Royal Botanical Gardens (K), EMBRAPA-CPATU (IAN) e Museu Emílio Goeldi (MG) e aos respectivos curadores; à Fundação Margarete Mee, pela concessão de bolsa ao primeiro autor.

\section{BIBLIOGRAFIA CITADA}

Cervi, A.C. 1997. Passifloraceae from Brazil. Studies of genus Passiflora L., subgenus Passiflora. Fontqueria, 45: 1-92 (in Portuguese, with abstract in English).

Cervi, A.C. 2006. The genus Passiflora L. (Passifloraceae) from Brazil, species described after the year 1950. Adumbrationes ad Summae Editionem, 16: 1-5 (in Portuguese, with abstract in English).

Cervi, A. C.; Milward-de-Azevedo, M. A.; Bernacci, L. C. 2010. Passifloraceae in List of species of flora from Brazil. Jardim Botânico do Rio de Janeiro. (http://floradobrasil.jbrj.gov. br/2010/FB000182). Acesso em 17/12/10 (in Portuguese and English).

Deginani, N.B. 2001. The species of Passiflora from Argentina (Passifloraceae). Darwiniana 39(1-2): 43-129 (in Spanish).

Feuillet, C. 2004. Passiflora phellos, a new species in Subgenus Passiflora (Passifloraceae). Novon, 14(3): 285-287.

Holm-Nielsen, L. B.; Jorgesen, P. M.; Lawesson, J. E. 1988. Flora of Ecuador: Passifloraceae, 31: 1-131.

Killip, E.P. 1938. The American species of Passifloraceae. Publications Field Museum of Natural History, Botanical Series 19(1-2): 1-613.

Ocampo, J.P.; Coppens d'Eeckenbrugge, G.; Restrepo, M.; Jarvis, A; Salazar, M.; Caetano, C. 2007. Diversity of colombian Passifloraceae: biogeography and an updated list for conservation. Biota Colombiana, 8 (1): 1- 45.

Ribeiro, J.E. da S.; Hopkins, M.J..G.; Vicentini, A.; Sothers, C.A.; Costa, M.A.; Brito, J.M.; Souza, M.A.D.; Martins, L.H.P. 1999. Flora da Reserva Ducke. Guia de identificação das plantas vasculares de uma floresta de terra firme na Amazônia Central. INPA, Manaus, AM, BRASIL. 799 pp.

Ulmer, T.; MacDougal, J.M. 2004. Passiflora: Passionflowers of the world. Timber Press, Portland-Cambridge, UK. 430 pp

Recebido em 13/08/2010

Aceito em 19/12/2010 